\title{
Perceptions and practices of Finnish dairy producers on disbudding pain in calves
}

\author{
A.-H. Hokkanen,${ }^{*} \dagger^{1}$ I. Wikman, ${ }^{*} \dagger$ T. Korhonen, $\dagger$ M. Pastell, ${ }^{*} \ddagger$ A. Valros,${ }^{*} \dagger$ O. Vainio, ${ }^{\star} \S$ and L. Hänninen ${ }^{*} \dagger$ \\ ${ }^{*}$ Research Centre for Animal Welfare, Faculty of Veterinary Medicine, PO Box 57, FI-00014 University of Helsinki, Finland \\ †Department of Production Animal Medicine, Faculty of Veterinary Medicine, PO Box 57, FI-00014 University of Helsinki, Finland \\ $\ddagger$ MTT Agrifood Research Finland, Koetilantie 5, Fl-00790 Helsinki, Finland \\ $\S$ Department of Equine and Small Animal Medicine, Faculty of Veterinary Medicine, PO Box 57, FI-00014 University of Helsinki, Finland
}

\section{ABSTRACT}

Disbudding causes pain-related distress and behavioral changes in calves. Local anesthesia and non-steroidal anti-inflammatory drugs are effective for treating disbudding-related pain. Dairy producers play a key role in whether or not calves to be disbudded are properly medicated. Pain and distress related to disbudding of calves often remains untreated. Thus, we conducted this study to characterize perceptions and practices of dairy producers on disbudding and disbudding-related pain management. A questionnaire was sent to 1,000 randomly selected Finnish dairy producers (response rate: $45 \%$ ). Our aim was to investigate producer perceptions about disbudding-related pain, the perceived need for pain alleviation before disbudding, and how these perceptions affect the valuing and use of pain alleviation before disbudding. More than $70 \%$ of Finnish dairy farms disbud their calves. Producers who ranked disbudding-related pain and need for pain alleviation higher called a veterinarian to medicate calves before disbudding more often than producers who ranked disbudding pain and need for pain alleviation lower. Among respondents who disbudded calves on their farms, $69 \%$ stated that disbudding caused severe pain, $63 \%$ stated that pain alleviation during disbudding is important, and $45 \%$ always had a veterinarian medicate their calves before disbudding. Producers with a herd healthcare agreement with their veterinarian estimated disbudding-related pain to be higher and had a veterinarian medicate calves more often than producers without such an agreement. Producers with tiestall systems and producers who did not use disbudding valued pain alleviation prior to disbudding higher than producers with freestalls and producers who used disbudding.

Key words: disbudding-related pain, producer perception, management practice, calf welfare

Received October 31, 2013.

Accepted October 20, 2014

${ }^{1}$ Corresponding author: ann-helena.hokkanen@helsinki.fi

\section{INTRODUCTION}

Disbudding, the removal of a calf's horn buds, is a common practice (ALCASDE, 2009) usually performed because hornless cattle are safer among themselves and humans (Prayaga, 2007; Duffield et al., 2008). The European Council (1988) Directive 98/58/EC allows any skilled person to destroy or remove the horn-producing area of animals aged less than 4 wk by chemical or heat cauterization, and no anesthesia or pain medication is required. In Finland, calves over 4 wk of age can be disbudded only by a veterinarian using adequate anesthesia (European Council, 1988; ALCASDE, 2009; Finlex, 2010).

Disbudding causes pain-related distress and behavioral changes in calves (Doherty et al., 2007; Heinrich et al., 2009; Stilwell et al., 2009). Local anesthesia (cornual nerve blocking) delays and alleviates the pain for $2 \mathrm{~h}$ (Graf and Senn, 1999), and nonsteroidal antiinflammatory drugs (NSAID) such as meloxicam (Heinrich et al., 2009; Stewart et al., 2009; Heinrich et al., 2010) and ketoprofen (McMeekan et al., 1998; Faulkner and Weary, 2000) are effective for treating disbudding-related pain postoperatively. For more information about disbudding-related pain alleviation, see the review by Stock et al. (2013).

Medical treatment is administered before or after calf disbudding on only $20 \%$ of European farms (ALCASDE, 2009). In Italy, producers reported that $10 \%$ of their disbudded calves received local anesthetics, $4 \%$ received a sedative, and 5\% received analgesics before disbudding, and the majority of respondents were not willing to pay for veterinary services to treat disbudding-related pain (Gottardo et al., 2011). In Canada, use of sedatives or local anesthetics before disbudding was reported for $45 \%$ of herds, but apparently no analgesics were used (Vasseur et al., 2010). In the United States, sedatives or local anesthetics were used by $12 \%$ and analgesics by $2 \%$ of dairy farmers (Fulwider et al., 2008).

Veterinarians agree that disbudding is painful (Hewson et al., 2007; Hudson et al., 2008; Norring et al., 
2014) but not all veterinarians alleviate pain before disbudding (Huxley and Whay 2006; Hewson et al., 2007; Misch et al., 2007). It is recommended to use sedatives, local anesthetics, and NSAID to alleviate disbuddingrelated pain (AVA, 2004; New Zealand Government, 2005; AVMA, 2012), but little is known about how well veterinarians follow these recommendations. Veterinarians are thought to be important consultants for farmers concerning animal health and welfare (Pothmann et al., 2014) and authority figures for producers (Kauppinen et al., 2010). Finnish producers have an opportunity to join a veterinary herd health management program (VHHM). In Finland, healthcare veterinarians make at least one annual nonemergency visit to their client farms to focus on possible improvement targets in herd health management and animal welfare (the NASEVA program; ETT ra, 2014). The NASEVA program is expected to increase the use of pain relief during disbudding because it strongly recommends that producers ask veterinarians to treat disbudded calves. However, no studies exist on whether producers who have a herd healthcare agreement use pain alleviation more than other producers. In Denmark, those producers who join VHHM are proactive and curious about new developments and information (Derks et al., 2012).

Because the use of pain alleviation before disbudding is not common (Fulwider et al., 2008; Vasseur et al., 2010; Gottardo et al., 2011) and producers are reported to be unwilling to pay for pain alleviation (Gottardo et al., 2011), more information about factors affecting a producer's choice in using pain alleviation is needed. In Finland, as in other Nordic countries, the use of veterinary drugs is highly restricted and legally controlled (Finlex, 1997); thus, motivation of the producer to use pain alleviation is especially important because use of sedatives, local anesthetics, and analgesic drugs requires veterinary intervention, incurring extra costs to the producer.

The aim of this study was to investigate producer perceptions about disbudding-related pain, the perceived need for pain alleviation before disbudding, and how these perceptions affect the valuing and use of pain alleviation before disbudding among dairy producers. In addition, information is lacking on how producers with different farm types (barn type, milk yield, herd size, having a herd healthcare agreement) differ regarding the use of pain alleviation before disbudding. We characterized management factors, perceptions, and practices of Finnish dairy producers on disbudding calves, the prevalence of disbudding on Finnish dairy farms, the producers' perceived need for pain alleviation, and the use of pain alleviation prior to disbudding. We expected that producers who estimated disbudding pain and the need for pain alleviation to be high would be more willing to pay a veterinarian to medicate their calves. Moreover, we expected that producers joining VHHM would also value and use pain alleviation more.

We previously showed that producers who took disbudding pain seriously (i.e., agreed that disbudding is very painful and that the pain should be treated) also estimated the pain caused by cattle disease to be more severe than the producers who did not rate disbudding pain highly (Wikman et al., 2013). However, it is not known if those producers intending to treat disbudding pain actually call on veterinary services to do so. The theory of planned behavior (Ajzen, 2002) has been used to study producers' motivation in herd health-related decision-making (Lind et al., 2012). The theory proposes that a producer's behavioral intention is strongly correlated with the actual behavior and the behavioral intention is related to attitude, subjective norm, and perceived behavioral control. We wanted to know, therefore, how many of those producers who think disbudding is painful and that pain needs to be treated actually call a veterinarian to medicate their calves.

\section{MATERIALS AND METHODS}

\section{Study Design and Subjects}

During spring 2010, a 4-page, postage-paid questionnaire was sent to 1,000 Finnish dairy producers. The research protocol was approved by the Finnish Agency for Rural Affairs. The producers were randomly selected from a geographically balanced list of all 11,244 dairy producers in Finland (Tike, 2009).

All data were managed and analyzed without identifying the respondents or their farms. This study is a part of larger study and the study protocol is described in detail in Wikman et al. (2013).

\section{Questionnaire}

The questionnaire consisted of 5 sections and included 70 questions (Supplemental File; http://dx.doi. org/10.3168/jds.2013-7668). The first section included background information on the respondent and their farm. Questions reported here included herd size, milk yield, type of housing, and whether the farm has a herd healthcare agreement with a veterinarian. The second section asked about the prevalence of disbudding and the prevalence of polled animals, dairy cows with horns, tipped adult cows, and dangerous situations because of cattle with horns in Finnish dairy farms. The third section was intended only for the farms performing disbudding and questions related to standard disbudding practices reported here included "Does the veterinarian 
medicate the calves for the disbudding on your farm?", "What pain alleviation does your veterinarian use on the calves prior to disbudding?" and "At which age are the calves disbudded on average on your farm?" The questions in the fourth section were intended for all producers, regardless of whether disbudding occurred on the farm. In this section, respondents rated their agreement with common disbudding-related statements on a 5-point Likert scale (Raekallio et al., 2003), in which 1 corresponded to complete disagreement and 5 to complete agreement. Statements reported here were "Disbudding without medication causes the calf pain," "The calf may feel pain for as long as $3 \mathrm{~d}$ after the disbudding procedure," "I could never disbud calves without any pain alleviation," "Medication eliminates pain during disbudding," "Painless disbudding increases calf welfare," "The calf requires no pain medication for disbudding," and "It is too expensive to have a veterinarian medicate the calf for disbudding."

In the fifth section, respondent opinion about the severity of the disbudding pain without any medication were sought using an 11-point numerical rating scale, with 0 representing no pain and 10 the worst pain imaginable (Huxley and Whay, 2006; Hudson et al., 2008; Kielland et al., 2009).

\section{Statistical Analysis}

In total, 451 of 1,000 questionnaires (45\%) were returned. Of all 451 respondents, 438 responses were included in the final analysis. Thirteen responses that systemically lacked answers to section 4 were excluded from the analysis.

The 11-point Likert-scale for evaluating calf pain during disbudding without any pain medication was further divided into 3 classes to describe respondents' overall perceptions and to help make comparisons with other similar studies (Hoe and Ruegg, 2006; Gottardo et al., 2011): mild pain $0-3$, moderate pain $4-7$, and severe pain $8-10$.

To describe respondents' overall perception about disbudding-related pain, and the perceived need for pain alleviation, 2 sum variables were created. First, to measure respondents' perception of disbudding-related pain, the respondents' opinions about the severity of the disbudding pain without any medication $(0-10)$ and the statements "Disbudding without medication causes the calf pain" (1-5) and "The calf may feel pain for as long as $3 \mathrm{~d}$ after the disbudding procedure" (1-5) were summed. Second, to describe respondents' perception of how important it is to treat pain (need for pain alleviation), a sum variable including the statements "I could never disbud calves without any pain alleviation" (1-5), "Medication eliminates pain during disbudding" (1-5),
"Painless disbudding increases calf welfare" (1-5), and "The calf requires no pain medication for disbudding," revised as "The calf requires pain medication for disbudding" (1-5), were created. Random missing values were replaced with a group-mean before sum variable formation. The sum variables were generated in the way that the maximum score of 20 represented a very high perception of pain and a very great need for pain alleviation. Minimum scores of 2 and 4 represented a very low perception of pain and need for pain alleviation.

Differences in the perception of pain, the need for pain alleviation among producers with different barn types (categorized as tiestalls and freestalls), and having a herd healthcare agreement with a veterinarian were tested with Mann-Whitney U-tests. A KruskalWallis test was first used to test for differences in the perception of pain and need for pain alleviation among farms with different mean annual milk yields (categorized as $\leq 8,000,8,001-10,000$, or $>10,000 \mathrm{~L} / \mathrm{yr}$ ), herd sizes (categorized as 1 to 20, 21 to 40, 41 to 60 , and $>61$ cows), and prevalence of having a veterinarian medicate calves before disbudding (always, sometimes, never); if statistically significant, the pair-wise comparisons were tested with a Mann-Whitney U-test using Bonferroni corrections.

Associations between the perception of pain and need for pain alleviation with producer willingness to pay for a veterinarian to medicate calves for disbudding ("It is too expensive to have a veterinarian medicate the calf for disbudding," scale 1-5; 1 corresponded with complete disagreement and 5 with complete agreement) were tested with Spearman rank correlation $\left(\mathbf{r}_{\mathrm{s}}\right)$.

The effects of studied farm factors (barn type, herd size, milk yield, and having herd healthcare agreement) on the prevalence of disbudding (yes or no) and having a veterinarian medicate calves before disbudding (always, sometimes, or never) were tested with the $\chi^{2}$ test. Results are presented as proportions of respondents and medians (interquartile range, IQR); software PASW 18.0.1 (2009; SPSS Inc., Chicago, IL) was used for all statistical analyses.

\section{RESULTS}

\section{Profile and Standard Disbudding Practices of All Respondents}

Descriptive results from the questionnaire are shown in Table 1. According to values for mean milk yield, mean herd size, and housing type, the survey respondents comprised a representative sample of Finnish dairy farmers. 
Table 1. Profile of the questionnaire respondents and the respective national figures representing farms belonging to the Finnish herd surveillance system; 451 (45\%) questionnaires were returned

\begin{tabular}{lcc}
\hline Profile of respondents & $\begin{array}{c}\text { Respondents } \\
(\%)\end{array}$ & $\begin{array}{c}\text { Finnish } \\
\text { average }\end{array}$ \\
\hline Herd size (no. of cows per farm) & & \\
$1-20$ & 46 & 28 \\
$21-40$ & 38 & \\
$41-60$ & 11 & \\
$>61$ & 5 & \\
Mean milk yield/cow per year (L) ${ }^{1}$ & 28 & 8,840 \\
$\leq 8,000$ & 56 & \\
$8,001-10,000$ & 16 & \\
$>10,000$ & & \\
Barn type & 73 & $76 \%$ \\
Tiestall & 27 & $24 \%$ \\
Freestall & 66 & $47 \%$ \\
Herd healthcare agreement ${ }^{2}$ &
\end{tabular}

${ }^{1}$ Tike (2009).

${ }^{2}$ ETT ra, The Association for Animal Disease Prevention (2010).

\section{Prevalence of Disbudding}

Disbudding of calves was practiced in $72 \%$ of the surveyed dairy farms. The majority of the calves (95\%) were disbudded at less than 4 wk of age (Table 2). Prevalence of polled animals, dairy cows with horns, tipped adult cows, and dangerous situations because of cattle with horns in Finnish dairy farms are shown in Table 2.

\section{Producers' Perceptions About Disbudding-Related Pain and the Perceived Need for Pain Alleviation}

Of the respondents, 5\% estimated that disbudding without pain medication caused only mild pain, $25 \%$ moderate pain, and 70\% severe pain. Respondents' agreements to disbudding-related statements are shown in Table 3. The median (IQR) of all 438 responses for "perception about disbudding-related pain" sum variable was 16.0 (5.0) and "perceived need for pain alleviation" was 15.0 (5.0).

Differences in Finnish dairy producers' prevalence of disbudding, having a herd healthcare agreement with a veterinarian, and barn type on the producers' median (IQR) perceptions of disbudding-related pain and the need for pain alleviation are shown in Table 4. Respondents who always had a veterinarian medicate their calves before disbudding estimated pain and the need for pain alleviation to be higher than producers who used a veterinarian sometimes or never $(P<0.01$ for all; Table 5).

From all 438 responses, producers' agreement (1-5; 1 as complete disagreement to 5 as complete agreement) with the statement "It is too expensive to have a veterinarian medicate calves prior to disbudding" correlated weakly and negatively with the respondents' pain estimation $\left(\mathrm{r}_{\mathrm{s}}=-0.38\right)$, and the perceived need for pain alleviation $\left(\mathrm{r}_{\mathrm{s}}=-0.46\right)(P<0.001$ for both $)$. Among those who disbudded calves on their farms, the respective correlations were $\mathrm{r}_{\mathrm{s}}=-0.46$ and $\mathrm{r}_{\mathrm{s}}=-0.58$ $(P<0.001$ for both $)$.

\section{Farms with a Herd Healthcare Agreement with a Veterinarian}

Disbudding was more common among respondents who had a herd healthcare agreement with a veterinarian $(\mathrm{n}=289)$ than among producers who did not have an agreement $(\mathrm{n}=145)[232 / 289(80 \%)$ disbudding vs. 80/145 (55\%) disbudding; $P<0.001]$. Having a herd healthcare agreement with a veterinarian had an effect on a producer's estimation of pain but not on the perceived need for pain alleviation (Table 4). Among producers who used disbudding, those who had a herd healthcare agreement with a veterinarian $(\mathrm{n}=232)$

Table 2. Prevalence of disbudding; the age of calves to be disbudded; the prevalence of polled cattle, tipped cows, and cows with horns; and dangerous situations caused by horns in Finnish dairy farms according to 451 (45\%) respondents

\begin{tabular}{|c|c|c|}
\hline Question & Response & Prevalence $(\%)$ \\
\hline \multirow{2}{*}{ Do you disbud on your farm? } & Yes, some of the calves & 34 \\
\hline & No & 28 \\
\hline \multirow{3}{*}{ At which age are the calves disbudded on average on your farm? } & $1-2$ wk & 27 \\
\hline & $2-4 \mathrm{wk}$ & 65 \\
\hline & $>4 \mathrm{wk}$ & 5 \\
\hline \multirow{2}{*}{ Do you have polled dairy cows? } & Yes & 19 \\
\hline & No & 81 \\
\hline \multirow{2}{*}{ Do you have tipped (horns sawn) dairy cows? } & Yes & 42 \\
\hline & No & 58 \\
\hline \multirow{2}{*}{$\begin{array}{l}\text { If you currently have or previously had cows with horns, do horns pose } \\
\text { any danger to humans }\end{array}$} & Yes & 69 \\
\hline & No & 31 \\
\hline
\end{tabular}


stated more often that a veterinarian always medicated their calves before disbudding compared with those producers $(\mathrm{n}=80)$ who did not have a herd healthcare agreement $[117 / 232(50 \%)$ with herd health agreement vs. $23 / 80$ (29\%) without; $P=0.006)$.

\section{Farm Factors}

Type of Housing. Disbudding was more commonly carried out on animals in freestalls than on those in tiestalls $(P<0.001)$ : altogether $62 \%$ of respondents with tiestalls $(\mathrm{n}=317)$ and $>99 \%$ of those with freestalls $(\mathrm{n}=118)$ disbudded on their farms. Producers with tiestalls estimated the need for pain alleviation to be higher compared with those with freestalls $(P<0.001)$. Type of housing had no effect on pain estimation $(P$ $=0.09$, Table 4$)$ or on having a veterinarian medicate calves before disbudding $(P=0.14)$.

Herd Size. Disbudding was less common among respondents who had a maximum of 20 cows $(51 \%, \mathrm{n}=$ 196) than among respondents with 21 to 40 cows $(86 \%$, $\mathrm{n}=162)$, 41 to 60 cows $(98 \%, \mathrm{n}=48)$, and $>60$ cows $(100 \%, \mathrm{n}=21 ; P<0.001$ for all). Producers with different mean herd sizes did not differ in their estimates of pain severity $(P=0.88)$ or in the perceived need for pain alleviation $(P=0.60)$. Farms with differing herd sizes did not differ in the use of a veterinarian to medicate calves before disbudding $(P=0.29)$.

Mean Milk Yield. Farms with different mean milk yields differed regarding disbudding $(P<0.001)$. Disbudding was less common on farms with mean milk yields of $\leq 8,000 \mathrm{~L}(47 \%, \mathrm{n}=120)$ than on farms with mean milk yields of 8,001 to $10,000 \mathrm{~L}(81 \%, \mathrm{n}=241)$ and $>10,000 \mathrm{~L}(84 \%, \mathrm{n}=70)$. Mean milk yield did not affect the producer's estimation of pain $(P=0.60)$ or the perceived need for alleviating disbudding pain $(P$ $=0.32$ ). The use of a veterinarian to always medicate calves before disbudding was less common for herds with annual milk yields of $<8,001 \mathrm{~L}(32 \%)$ than for herds with milk yields of $>10,000 \mathrm{~L}(60 \% ; P=0.02)$.

\section{Respondents Using Disbudding: Disbudding-Related Pain, Need for Pain Alleviation, and Use of Pain Alleviation}

According to respondents, $91 \%$ of Finnish veterinarians use sedatives, $83 \%$ local anesthetics, and $48 \%$ NSAID. Only $4 \%$ of respondents stated that they did not know what medications their veterinarian used. The perception of pain, perceived importance of pain alleviation, and the actual use of pain alleviation before disbudding among Finnish producers who used disbudding are shown in Figure 1.

\section{DISCUSSION}

We demonstrate here that producers who rank disbudding-related pain and the need for pain alleviation high also value pain alleviation more and are more willing to have a veterinarian medicate their calves before disbudding compared with producers who rank pain and the need for pain alleviation lower. This relationship with producers' perceptions of disbudding pain and their willingness to use pain alleviation for calves is in line with a study conducted among Canadian veterinarians: those veterinarians who perceived dehorning without analgesia to be painful were more likely to use analgesics (Hewson et al., 2007). In addition, we found that producers who perceive pain and need for pain alleviation high find pain alleviation less expensive than those who perceive pain and need for pain alleviation lower.

Disbudding was a common procedure in Finland as in other European countries (ALCASDE, 2009; Gottardo et al., 2011). Disbudding was more common in larger herds than in smaller herds, as also reported for other countries (Hoe and Ruegg 2006; Vasseur et al., 2010; Gottardo et al., 2011). Almost all dairy farms with freestalls practiced disbudding, whereas the prevalence of disbudding was lower for cattle in tiestalls. These differences are probably due to work-safety issues, because

Table 3. Opinions of Finnish dairy producers on the statements concerning disbudding and disbudding-related pain management

\begin{tabular}{|c|c|c|c|c|c|c|}
\hline Statement about disbudding & No. & $\begin{array}{c}\text { Agree } \\
(\%)\end{array}$ & $\begin{array}{l}\text { Somewhat } \\
\text { agree }(\%)\end{array}$ & $\begin{array}{l}\text { Cannot } \\
\text { say }(\%)\end{array}$ & $\begin{array}{c}\text { Somewhat } \\
\text { disagree }(\%)\end{array}$ & $\begin{array}{l}\text { Disagree } \\
\quad(\%)\end{array}$ \\
\hline Disbudding without medication causes the calf pain & 435 & 57 & 18 & 15 & 6 & 4 \\
\hline The calf requires no pain medication for disbudding & 427 & 5 & 9 & 17 & 19 & 50 \\
\hline $\begin{array}{l}\text { It is too expensive to have a veterinarian medicate } \\
\text { the calf for disbudding }\end{array}$ & 435 & 42 & 16 & 10 & 7 & 25 \\
\hline Medication eliminates pain during disbudding & 425 & 30 & 33 & 26 & 8 & 3 \\
\hline
\end{tabular}




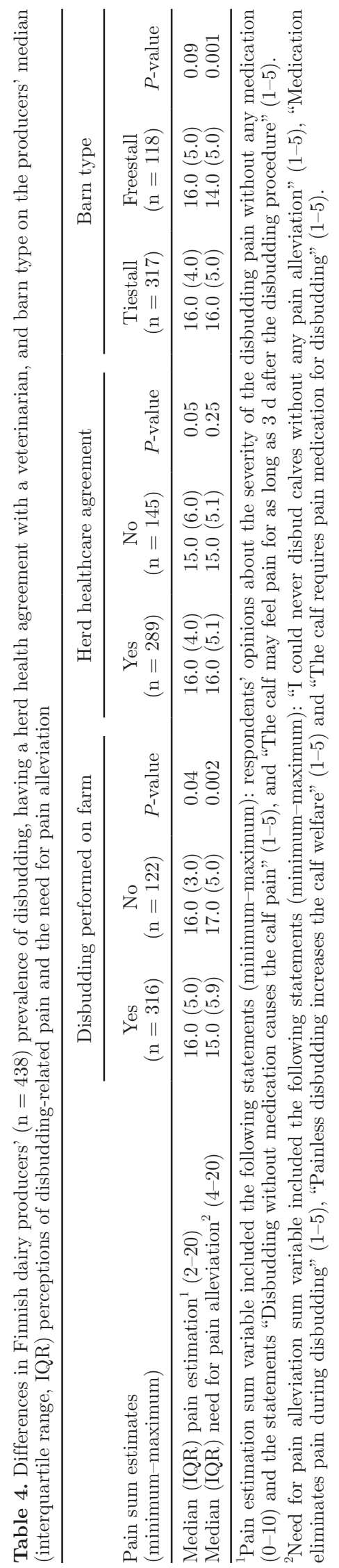

it is safer to work with hornless cattle in larger herds and herds with freestalls.

Producers with a herd healthcare agreement estimated the pain to be higher than those without such an agreement, but we observed no difference in the perceived need for pain alleviation between the 2 classes. Participation in a VHHM was previously shown to affect producer decision-making in herd health management (Lind et al., 2012). We also found that pain alleviation was used more among those producers with a herd healthcare agreement. Results may partly reflect the education given to producers by their own herd healthcare veterinarians, but also the built-in recommendation within the veterinary herd management program on the use of pain medication for disbudded calves. It is also possible that those producers who have more knowledge about herd health and management may be more willing to pay for herd health services, including for disbudding-related pain management.

Our results support the statement that horned cattle cause injuries to other animals and to humans (Prayaga, 2007): almost $70 \%$ of respondents stated that horns have caused dangerous situations for humans on their farms. Breeding polled cattle is an alternative solution to disbudding-related welfare problems (Prayaga, 2007). In our study, $20 \%$ of respondents had polled animals in their herd. The most common dairy cattle breeds in Finland are Ayrshire, Holstein, and Finnish Cattle (Tike, 2009), of which the latter are usually polled. One alternative to disbudding is tipping the adult cattle; that is, blunting the horns (Prayaga, 2007). Tipping was quite common: $42 \%$ of the respondents had tipped adult dairy cows in their herd.

Producers with tiestalls estimated the need for pain alleviation to be higher than did producers with freestalls, although producers with the 2 different housing systems did not differ regarding pain estimation. Because producers with freestalls also practiced disbudding more and usually had larger herds than producers with tiestalls, we suggest that Finnish dairy producers with freestalls might consider disbudding to be a more routine and essential procedure than those operating tiestalls. Our suggestion is further emphasized by the finding that the producers who did not use disbudding estimated the need for pain alleviation to be higher than those who did disbud on their farms.

We found no differences associated with different herd sizes for pain estimation or the need for disbudding pain alleviation among dairy producers, as also reported by Gottardo et al. (2011). Moreover, mean milk yield did not affect producers' pain estimation or the perceived need for pain alleviation, although it was invariably more common to ask a veterinarian to medicate calves before disbudding in herds where milk 
Table 5. Differences in the frequency of dairy producers $(\mathrm{n}=294)$ having a veterinarian medicate their calves before disbudding on the producers' median (interquartile range, IQR) perceptions of pain estimation and need for pain alleviation

\begin{tabular}{llll}
\hline Pain sum estimates (minimum-maximum) & $\begin{array}{c}\text { Always } \\
(\mathrm{n}=141)\end{array}$ & $\begin{array}{c}\text { Sometimes } \\
(\mathrm{n}=42)\end{array}$ & $\begin{array}{c}\text { Never } \\
(\mathrm{n}=111)\end{array}$ \\
\hline Median (IQR) pain estimation $^{1}(2-20)$ & $18.0(2.0)^{\mathrm{a}}$ & $16.0(3.3)^{\mathrm{b}}$ & $14.0(7.0)^{\mathrm{c}}$ \\
Median (IQR) need for pain alleviation $^{2}(4-20)$ & $18.0(3.0)^{\mathrm{a}}$ & $14.0(3.3)^{\mathrm{b}}$ & $12.8(4.0)^{\mathrm{c}}$ \\
\hline
\end{tabular}

${ }^{a-c}$ Different letters in a row indicate statistically significant differences $(P<0.01$ for all).

${ }^{1}$ Pain estimation sum variable included the following statements (minimum-maximum): respondents' opinions about the severity of the disbudding pain without any medication (0-10) and the statements "Disbudding without medication causes the calf pain" (1-5), and "The calf may feel pain for as long as $3 \mathrm{~d}$ after the disbudding procedure" (1-5).

${ }^{2}$ Need for pain alleviation sum variable included the following statements (minimum-maximum): "I could never disbud calves without any pain alleviation" (1-5), "Medication eliminates pain during disbudding" (1-5),

"Painless disbudding increases calf welfare" (1-5) and "The calf requires pain medication for disbudding" (1-5).

yields exceeded 10,000 L/yr than for those producing $<8,001 \mathrm{~L} / \mathrm{yr}$. This finding is similar to those of other studies in which higher milk yields were reported to be associated with positive attitudes toward human-animal interactions (Hanna et al., 2009).

Although we show here that if a producer estimates pain and the need for pain alleviation to be high, he or she is more likely to use pain alleviation before disbudding, not all producers who estimated pain as high and pain alleviation as important used a veterinarian to medicate calves, as shown in Figure 1. Some farms in remote areas may face difficulties in accessing nonemergency veterinary services. Many producers stated that it is too expensive to call a veterinarian to medicate calves. The costs might limit the use of pain medication, especially for farms with economic problems. It is also possible that the person answering our questionnaire was not the same person who decided if disbudded calves were medicated on the farm. More research is needed to explain the reasons behind this behavior and to find ways to increase the use of pain alleviation.

Overall, the use of pain alleviation in Finland was higher than reported in previous surveys conducted in the United States, Canada, and Italy (Hoe and Ruegg 2006; Vasseur et al., 2010; Gottardo et al., 2011). Although it is difficult to compare practices among different countries because restrictions on the use of drugs differ, our findings support the idea that a keen perception of pain increases the use of pain alleviation. In the United States, $50 \%$ of dairy producers believed that disbudding caused "moderate" or "a lot" of pain and only $18 \%$ used some pain alleviation (Hoe and Ruegg,

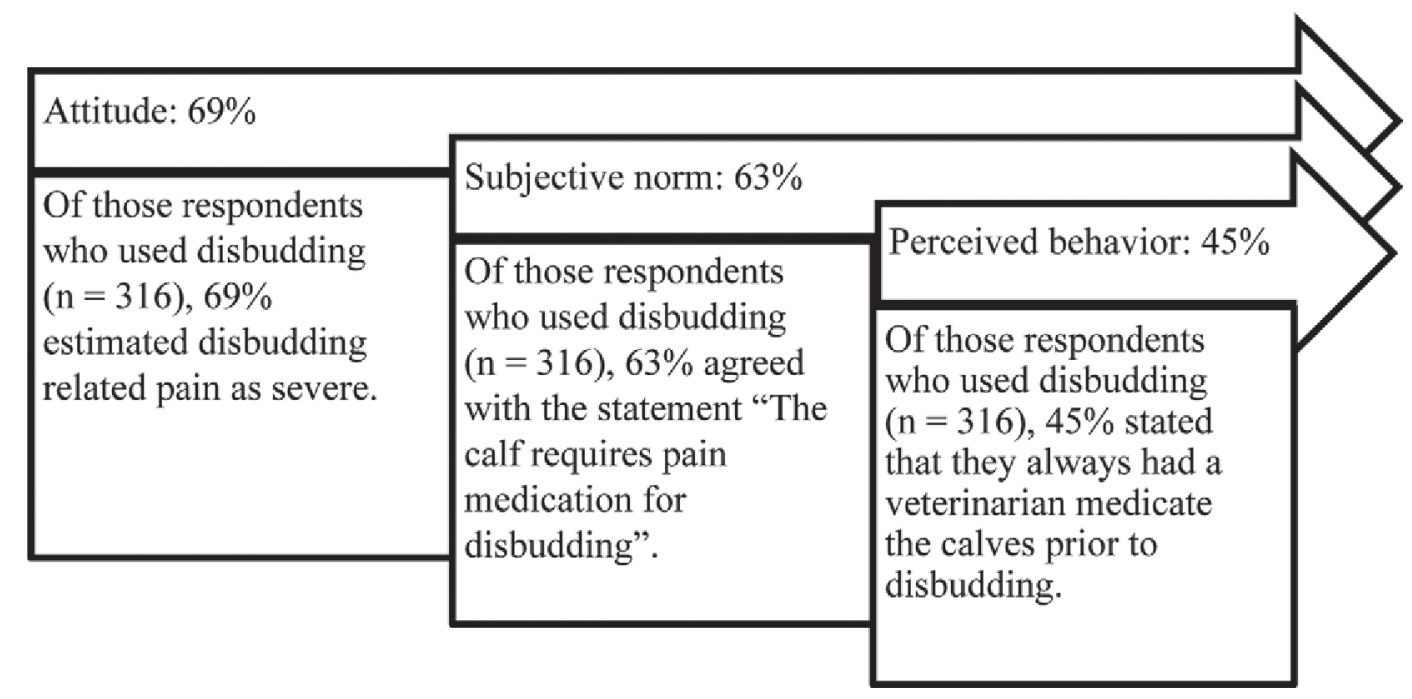

Figure 1. Finnish dairy producers' estimation of pain, estimated need for pain alleviation, and use of pain alleviation before disbudding based on the theory of planned behavior (Ajzen, 2002). The theory of planned behavior (Ajzen, 2002) has been used to study producers' motivation in herd health-related decision-making (Lind et al., 2012). The theory proposes that a producer's behavioral intention is strongly correlated with the actual behavior and the behavioral intention is related to attitude, subjective norm, and perceived behavioral control. 
2006). In Italy, over $40 \%$ of the farmers regarded postdisbudding pain as moderate, lasting up to $6 \mathrm{~h}$, and $10 \%$ used local anesthetics (Gottardo et al., 2011). Studies on disbudding-related pain previously concentrated on the $48 \mathrm{~h}$ after the procedure. Some recent evidence suggests that the pain might last longer than $48 \mathrm{~h}$ (Mintline et al., 2013). One-third of producers in our study agreed that the pain might last for at least $3 \mathrm{~d}$.

Half of the respondents stated that veterinarians did not use NSAIDs. However, this was somewhat contradictory to our previous finding in which veterinarians oriented toward production-animal practice and young veterinarians treat disbudding pain in calves according to national recommendations, with sedatives, local anesthetics, and NSAIDs (Norring et al., 2014). Obviously, education of Finnish veterinarians working in the field could be improved further. It is also possible that the producers were not aware of what medication the calf is given during disbudding.

Almost all of the respondents that disbudded indicated that, on their farms, calves were disbudded before 4 wk of age whether or not they used pain alleviation (i.e., a veterinarian to medicate calves). This contradicts findings of similar studies in Italy and North America. In Italy, the mean age at disbudding was slightly over 4 wk, but only one-quarter of the surveyed farms disbudded their calves within the third week of life (Gottardo et al., 2011). In Canada, the median age for disbudding was slightly over $6 \mathrm{wk}$ (Vasseur et al., 2010) and $8 \mathrm{wk}$ in the United States (Fulwider et al., 2008). Age at disbudding is a critical factor in limiting pain related to the procedure because the horn buds are smaller and free-floating in the skin layer above the skull up until about 8 wk of age (Parsons and Jensen, 2006). In Finland, legislation may play a role; producers might think that calves have to be disbudded before $4 \mathrm{wk}$ of age whether or not pain alleviation is used, although legislation allows disbudding with pain alleviation also for calves older than $4 \mathrm{wk}$ of age if performed by a veterinarian.

\section{CONCLUSIONS}

Producers who ranked disbudding-related pain and the need for pain alleviation high also valued and used veterinary services more often to medicate calves before disbudding. Producer perceptions about disbuddingrelated pain and the need for pain alleviation influenced their practices regarding disbudding-related pain alleviation. We suggest that educating producers about painful procedures, calf pain-related behaviors, and pain management in calves could increase the application of pain medication before disbudding.

\section{ACKNOWLEDGMENTS}

Funding for this study was provided by the Ministry of Agriculture and Forestry in Finland (Helsinki). We thank our sponsors Valio Ltd. (Helsinki, Finland), Vetman Ltd. (Halikko, Finland), Viking Genetics (Hollola, Finland), and Osuuskunta Maitosuomi (Seinäjoki, Finland). Tanja Korhonen thanks Hämäläis-Osakunta for a personal grant. We also thank veterinarian Kati Salla and PhD Tiina Kauppinen for their valuable help throughout this project. We warmly thank all of the dairy producers in Finland who participated in this study. The authors declare that they have no competing interests.

\section{REFERENCES}

Ajzen, I. 2002. Perceived behavioral control, self-efficacy, locus of controls and theory of planned behavior. J. Appl. Soc. Psychol. 32:665-683.

ALCASDE (Alternatives to Castration and Dehorning). 2009. Final report: Study on the improved methods for animal-friendly production, in particular on alternatives to the castration of pigs and on alternatives to the dehorning of cattle. SANCO/2008/D5/018. Accessed Aug. 24, 2012. http://ec.europa.eu/food/animal/ welfare/farm/alcasde_study_04122009_en.pdf.

AVA (Australian Veterinary Association). 2004. Policy Compendium on Cattle Health and Welfare. Accessed Apr. 22, 2013. http:// www.ava.com.au/policy/84-dehorning-cattle.

AVMA (American Veterinary Medical Association). 2012. Welfare implications of dehorning and disbudding of cattle. Accessed Apr. 22, 2013. https://www.avma.org/KB/Policies/Pages/CastrationandDehorning-of-Cattle.aspx.

Derks, M., L. M. A. Van de Ven, T. Van Werven, W. D. J. Kremer, and H. Hogeveen. 2012. The perception of veterinary herd health management by Dutch dairy farmers and its current status in the Netherlands: A survey. Prev. Vet. Med. 104:207-215.

Doherty, T. J., H. G. Kattesh, R. J. Adcock, M. G. Welborn, A. M. Saxton, J. L. Morrow, and J. W. Dailey. 2007. Effects of a concentrated lidocaine solution on the acute phase stress response to dehorning in dairy calves. J. Dairy Sci. 90:4232-4239.

Duffield, T. 2008. Current data on dehorning calves. Pages 25-28 in 41st Annu. Conv. Proc. Am. Assoc. Bovine Pract., Charlotte, NC. Am. Assoc. Bovine Pract., Auburn, AL.

ETT ra. 2010. The Association for Animal Disease Prevention. Accessed Nov. 16, 2014. http://www.ett.fi/sisalto/naseva-cattlehealth-care-register.

European Council. 1988. Recommendations concerning cattle adopted by the Standing Committee. Accessed Oct. 30, 2013. http://www. coe.int/t/e/legal_affairs/legal_co-operation/biological_safety_ and_use_of_animals/farming/Rec\%20cattle\%20E.asp.

Faulkner, P. M., and D. M. Weary. 2000. Reducing pain after dehorning in dairy calves. J. Dairy Sci. 83:2037-2041.

Finlex. 1997. Act on the Medical Treatment of Animals 617/1997 by the Council of State on 27th of June 1997, Finland. Accessed Apr. 22, 2013. http://www.finlex.fi/fi/laki/ajantasa/1997/1997061. [Legislation in Finnish].

Finlex. 2010. Cattle Welfare Decree $592 / 2010$ by the Council of State on 10th of July 2010, Finland. Accessed Apr. 22, 2013. http:// www.finlex.fi/fi/laki/ajantasa/2010/20100592. [Legislation in Finnish]

Fulwider, W. K., T. Grandin, B. E. Rollin, T. E. Engle, N. L. Dalsted, and W. D. Lamm. 2008. Survey of dairy management practices on one hundred thirteen North Central and Northeastern United States dairies. J. Dairy Sci. 91:1686-1692. 
Gottardo, F., E. Nalon, B. Contiero, S. Normando, P. Dalvit, and G. Cozzi. 2011. The dehorning of dairy calves: Practices and opinions of 639 farmers. J. Dairy Sci. 94:5724-5734.

Graf, B., and M. Senn. 1999. Behavioural and physiological responses of calves to dehorning by heat cauterization with or without local anaesthesia. Appl. Anim. Behav. Sci. 62:153-171.

Hanna, D., I. A. Sneddon, and V. E. Beattie. 2009. The relationship between the stockperson's personality and attitudes and the productivity of dairy cows. Animal 3:737-743.

Heinrich, A., T. F. Duffield, K. D. Lissemore, and S. T. Millman. 2010. The effect of meloxicam on behavior and pain sensitivity of dairy calves following cautery dehorning with a local anesthetic. J. Dairy Sci. 93:2450-2457.

Heinrich, A., T. F. Duffield, K. D. Lissemore, E. J. Squires, and S. T. Millman. 2009. The impact of meloxicam on postsurgical stress associated with cautery dehorning. J. Dairy Sci. 92:540-547.

Hewson, C. J., I. R. Dohoo, K. A. Lemke, and H. W. Barkema. 2007. Factors affecting Canadian veterinarians' use of analgesics when dehorning beef and dairy calves. Can. Vet. J. 48:1129-1136.

Hoe, F. G. H., and P. L. Ruegg. 2006. Opinions and practices of Wisconsin dairy producers about biosecurity and animal well-being. J. Dairy Sci. 89:2297-2308.

Hudson, C., H. Whay, and J. Huxley. 2008. Recognition and management of pain in cattle. In Pract. 30:126-134.

Huxley, J. N., and H. R. Whay. 2006. Current attitudes of cattle practitioners to pain and the use of analgesics in cattle. Vet. Rec. 159:662-668.

Kauppinen, T., A. Vainio, A. Valros, H. Rita, and K. M. Vesala. 2010. Improving animal welfare: Qualitative and quantitative methodology in the study of farmers' attitudes. Anim. Welf. 19:523-536.

Kielland, C., E. Skjerve, and A. J. Zanella. 2009. Attitudes of veterinary students to pain in cattle. Vet. Rec. 165:254-258.

Lind, A.-K., P. T. Thomsen, S. Rintakoski, M. N. Espetvedt, C. Wolff, and H. Houe. 2012. The association between farmers' participation in herd health programmes and their behavior concerning treatment of mild clinical mastitis. Acta Vet. Scand. 2:54-62.

McMeekan, C. M., K. J. Stafford, D. J. Mellor, R. A. Bruce, R. N Ward, and N. G. Gregory. 1998. Effects of regional analgesia and/ or a non-steroidal anti-inflammatory analgesic on the acute cortisol response to dehorning in calves. Res. Vet. Sci. 64:147-150.

Mintline, E. M., M. Stewart, A. R. Rogers, N. R. Cox, G. A. Verkerk, J. M. Stookey, J. R. Webster, and C. B. Tucker. 2013. Play behavior as an indicator of animal welfare: Disbudding in dairy calves. Appl. Anim. Behav. Sci. 144:22-30.

Misch, L. J., T. F. Duffield, S. T. Millman, and K. D. Lissemore 2007. An investigation into the practices of dairy producers and veterinarians in dehorning dairy calves in Ontario. Can. Vet. J. 48:1249-1254.

New Zealand Government. 2005. Animal Welfare (Painful Husbandry Procedures) Code of Welfare 2005. Accessed Apr. 22, 2013 http://www.biosecurity.govt.nz/files/regs/animal-welfare/req/ codes/painful-husbandry/painful-husbandry.pdf.

Norring, M., I. Wikman, A.-H. Hokkanen, M. V. Kujala, and L. Hänninen. 2014. Empathic veterinarians score cattle pain higher. Vet. J. 200:186-190

Parsons, C., and S. Jensen. 2006. Dehorning Cattle, Western Beef Resource Committee, Cattle Producer's Library, Management Section CL750, University of Idaho and Oregon State University.

Pothmann, H., K. Nechanitzky, F. Sturmlechner, and M. Drillich. 2014. Consultancy to dairy farmers relating to animal health and herd health management on small- and medium sized farms. J. Dairy Sci. 97:851-860.

Prayaga, K. C. 2007. Genetic options to replace dehorning in beef cattle-A review. Aust. J. Agric. Res. 58:1-8.

Raekallio, M., K. M. Heinonen, J. Kuussaari, and O. Vainio. 2003 Pain alleviation in animals: Attitudes and practices of Finnish veterinarians. Vet. J. 165:131-135.

Stewart, M., J. M. Stookey, K. J. Stafford, C. B. Tucker, A. R. Rogers, S. K. Dowling, G. A. Verkerk, A. L. Schaefer, and J. R. Webster. 2009. Effects of local anesthetic and a nonsteroidal antiinflammatory drug on pain responses of dairy calves to hot-iron dehorning. J. Dairy Sci. 92:1512-1519.

Stilwell, G., R. C. de Carvalho, M. S. Lima, and D. M. Broom. 2009. Effect of caustic paste disbudding, using local anaesthesia with and without analgesia, on behaviour and cortisol of calves. Appl. Anim. Behav. Sci. 116:35-44.

Stock, M. L., S. L. Baldridge, D. Griffin, and J. F. Coetzee. 2013 Bovine dehorning: Assessing pain and providing analgesic management. Vet. Clin. North Am. Food Anim. Pract. 29:103-133.

Tike. 2009. Information Center of the Ministry of Agriculture and Forestry. Accessed Nov. 16, 2014. http://www.maataloustilastot. fi/el\%C3\%A4intuotanto_fi.

Vasseur, E., F. Borderas, R. I. Cue, D. Lefebvre, D. Pellerin, J. Rushen, K. M. Wade, and A. M. de Passillé. 2010. A survey of dairy calf management practices in Canada that affect animal welfare. J. Dairy Sci. 93:1307-1315.

Wikman, I., A.-H. Hokkanen, M. Pastell, T. Kauppinen, A. Valros, and L. Hänninen. 2013. Dairy producer attitudes to pain in cattle in relation to disbudding calves. J. Dairy Sci. 96:6894-6903. 